\title{
Underestimating Intraspecific Variation: The Problem With Excluding Sts 19 From Australopithecus africanus
}

\author{
J AMES C.M. AHERN* \\ Department of Anthropology, University of Michigan, \\ Ann Arbor, Michigan 48109-1382 \\ KEY WORDS species; polymorphism; Sterkfontein, \\ austral opithecines; Homo habilis
}

\begin{abstract}
Two analyses conclude that Sts 19 cannot be accommodated within the Australopitheaus africanus hypodigm (Kimbel and Rak [1993] In Kimbel and Martin [eds.]: Spedies, Spedies Concepts, and Primate Evolution. New York: Plenum, pp. 461-484; Sarmiento [1993] Am. J . Phys. Anthropol. [Suppl.] 16:173). Both studies exclude Sts 19 because it possesses synapomorphies with Homo. Furthermore, according to Kimbel and Rak (1993), including Sts 19 in A. africanus results in an unacceptably high degree of polymorphism.

This study aims to refute the null hypothesis that Sts 19 belongs to $A$. africanus. Twelve basicranial characters, as defined and implemented in Kimbel and Rak's study, were scored for casts of seven A. africanus and seven Homo habilis basi cranial specimens. These characters were also examined on specimens from a large $(\mathrm{N}=87)$ sample of African pongids. Contrary to Kimbel and Rak's (1993) findings, the null hypothesis is not refuted. The degree of polymorphism among $A$. africanus with Sts 19 included is less than that seen in Pan troglodytes. In addition, Sts 19 shares only one apomorphy with Homo. However, when treated metrically, Sts 19's morphology for this character is not significantly divergent from other A. africanus specimens. Am J PhysAnthropol 105:461-480, 1998. @ 1998 Wiley-Liss, Inc.
\end{abstract}

In recent years many researchers have questioned the validity of Australopithecus africanus as a distinct taxon (e.g., Clarke, 1988; Kimbel and White, 1988; Kimbel and Rak, 1993; Sarmiento, 1993). Unlike some earlier critiques of the taxon that saw it as encompassing too little variation (e.g., Tobias, 1980; Wolpoff, 1971a), recent analyses claim that $A$. africanus encompasses more than one species. Most of the debate surrounding variation in $\mathrm{A}$. africanus has dealt with the specimens from Sterkfontein Members 4 and 5. Clarke (1988) posits that the Member 4 specimen Stw 252 represents a second species, one that is directly ancestral to Australopithecus robustus. Hughs and Tobias (1977) and Clarke (1985) assign Stw 53 to Homo, which is Member 5 or older in age (Clarke, 1994; Kuman, 1994).
Clarke (1977) originally suggested that the Member 4 basicranial specimen, Sts 19 , may represent the genus Homo. This interpretation has been supported by both Sarmiento (1993) and Kimbel and Rak (1993). Sarmiento (1993) contends that Sts 19 shares affinities with both Homo and A. robustus. Kimbel and Rak (1993) argue that Sts 19 can beclearly linked to Homo, because it possesses synapomorphies and symplesiomorphies with Homo habilis to the exclusion of $A$. africanus. Furthermore, they posit that indudingSts 19 in A. africanus results in an unacceptably high degree of polymorphism.

\footnotetext{
Contract grant support: H. Rackham School of Graduate Studies, University of Michigan.

*Correspondenceto: J ames C.M. Ahern, Department of Anthropology, 1020 LSA, University of Michigan, Ann Arbor, MI 481091382. Fax: (313) 763-6077. e-mail: jachap@umich.edu

Received 27 J anuary 1997; accepted 31 December 1997.
} 
These interpretations are in contrast with those of the original describers of the Sterkfontein material and many more recent analyses. Broom and Robinson (1950), who saw the Sterkfontein specimens as a separate genus from Taung, believed that all of the Sterkfontein Member 4 material be longed to the same species, Plesianthropus transvaalensis. They recognized some "derived" features (e.g., a shortened cranial base) on Sts 19 (their Skull \#8), but felt content to include it with the rest of the Member 4 specimens. Holloway $(1970,1973)$ reported an estimated cranial capacity of $436 \mathrm{~cm}^{3}$, based solely upon the Sts 19 basicranium (the Sts 58 parietals which Broom and Robinson associated with Sts 19 were not used for this estimate). Such a cranial capacity falls well within therange of $A$. africanus and out of the range of $\mathrm{H}$. habilis. More recently, Dean and Wood (1982) in a metric study of Plio-Pleistocene basicrania concluded that Sts 19 can be accommodated within A. africanus. They support Clarke's (1977) second explanation of Sts 19: that the marked differences between it and Sts 5 merely indicate that $A$. africanus was a highly variable species.

The apparent change in Sts 19's designation stems from the recent increase in interest about species concepts and their application to paleoanthropology (as demonstrated by the vol ume edited by Kimbel and Martin, 1993). Species concepts of the past 50 years have attempted to address the ontological short-comings of Mayr's (1957) Biological Species Concept. Specifical ly, Biological Spe cies are static units having only a spatial dimension. Thus they are not comparable to phyletic lineages which have both spatial and temporal dimensions. The traditional approach in paleoanthropology has been to make arbitrary divisions of lineages into chronospecies (e.g., Brace, 1988; Gingerich, 1984; Rose and Bown, 1993). Although such arbitrary divisi ons are intended to be comparable to biological species, they are not discrete biological units. While some alternative species concepts have sunk multiple hominid chronospecies into a single lineagespecies (e.g., Wolpoff et al., 1994), others have actually split up traditional hominid taxa. The Phylogenetic Species Concept, which theoretically recognizes the minimum diagnosablebiological unit, has been particularly proficient at dividing traditional species (e.g., Kimbel, 1991; Kimbel and Rak, 1993; Tattersall, 1986, 1992, 1994). Cracraft defines a phylogenetic species as one that "is an irreducible cluster of organisms, diagnosably distinct from other such clusters, and within which there is a parental pattern of ancestry and descent" (1989:34-35). Thus one or more autapomorphies and/or a unique pattern of synapomorphies and plesiomorphies define a species.

Kimbel and Rak's (1993) application of the Phylogenetic Species Concept to specimens attributed to $A$. africanus results in the recognition of two species. Although others have addressed the inherent shortcomings of this species concept (e.g., E reshefsky, 1989; Mayden, 1997; Mayden and Wood, 1995; Rose and Bown, 1993; Wol poff, 1994, 1996), this study focuses specifically on theinconsistencies in its application to variation in A. africanus. This study attempts to replicate Kimbel and Rak's (1993) results using their characters and character states, a comparable hominid sample, and a large sample of the two pongid species used in their study. The null hypothesis that Sts 19 can be accommodated within the A. africanus hypodigm is tested.

\section{MATERIALS}

Kimbel and Rak's (1993) conclusion that Sts 19 represents a separate species is based entirely upon basicranial characters. In this study, 12 characters, as defined by Kimbel and Rak (1993), were examined on crania from four species: Gorilla gorilla, Pan troglodytes, $A$. africanus, and $\mathrm{H}$. habilis. The pongid samples (Appendix A), which were used as the outgroups in this analysis, consisted of 87 specimens from the collections of the Cleveland Museum of Natural History, the American Museum of Natural History, and the Paleoanthropology Laboratory of the University of Michigan. Sex of the specimens was based on the specimen files corroborated by the author's own observations. Among the Pan sample, 26 specimens were male and 22 were female. Nineteen Gorilla specimens were male and 20 were female. Only dentally adult individuals (those with 
TABLE 1. Thehominid samples ${ }^{1}$

\begin{tabular}{lll}
\hline \multicolumn{1}{c}{ Taxon } & \multicolumn{1}{c}{ Site } & \multicolumn{1}{c}{ Specimen } \\
\hline Australopithecus africanus & $\begin{array}{l}\text { Makapansgat } \\
\text { Sterkfontein }\end{array}$ & MLD 37/38 \\
& & Sts 5 \\
& & Sts 71 \\
& Stw 505 \\
Homo habilis & TM 1511 \\
& Koobi Fora & ER 1813 \\
& Olduvai & OH 3891 \\
& OH 13 & OH 24 \\
& Omo & L. 894-1 \\
& Sterkfontein & Stw 53 \\
Stw question & Swartkrans & SK 847 \\
& Sterkfontein & Sts 19 \\
\hline
\end{tabular}

${ }^{1}$ All but one of the hominid specimens were examined as casts housed in the Paleoanthropol ogy Laboratory of the University of Michigan. Omo L. 894-1 was examined at the Cleveland Museum of Natural History.

$M^{3}$ in occlusion) were used in the character state analysis, although juveniles and subadults were examined to establish the ontogeny of certain character states. Kimbel and Rak (1993) did not provide sizes or consistencies of their Pan and Gorilla samples, which were from the Hamann-Todd collection of the Cleveland Museum of Natural History.

Table 1 lists the hominid sample. The A. africanus sample differs from that used by Kimbel and Rak (1993) in that casts of Sts 25 and Stw 266 were not available for study. Although Kimbel and Rak (1993) included the Taung endocast in their sample, it was excluded from the character state analysis in this study because of its young age and because the available casts only exhibited two of the 12 characters used in this study. However, Taung was examined to investigate Eustachian process (character 11) ontogenetic variation in A. africanus. Finally, Stw 505 was included here since it preserves most of the glenoid fossa characters used in this study and shares many similarities in facial anatomy with the other Member 4 specimens. It was not included in Kimbel and Rak's (1993) analysis.

Choosing specimens appropriate for a $\mathrm{H}$. habilis sample was exceedingly difficult, since the composition of this hypodigm is still the focus of considerable debate (e.g., Wood, 1993; Kramer et al., 1995). The H. habilis sample was modeled after that used by Kimbel and Rak (Kimbel, pers. comm.). Two specimens used by Kimbel and Rak (1993) were not examined in this study:
KNM-ER 3735d and OH 16. The KNM-ER 3735d temporal was not included in the $\mathrm{H}$. habilis sample since it was not available for study. Furthermore, none of the characters used in this study were apparent on the National Museums of Kenya cast of $\mathrm{OH} 16$, although the original specimen does preserve the glenoid region. One specimen, SK 847 , was included in this study's H. habilis sample but was excluded in the Kimbel and Rak (1993) study. This specimen has been classified as a female robust australopithecine (Wolpoff, 1971b) and as Homo erectus (Clarke, 1977). However, Grine et al. (1993) have convincingly shown that SK 847 does not share affinities with either of these groups, but rather should be classified as $\mathrm{H}$. habilis, a classification earlier posited by Howell (1978). Another specimen, Stw 53, that was used in both this study and by Kimbel and Rak (1993) is of unclear taxonomic affinity. Although Wol poff (1996) classifies Stw 53 as late A. africanus, Hughs and Tobias (1977), Clarke (1985), and Kimbel and Rak (1993) place it in Homo habilis.

\section{METHODS \\ Characters and character states}

Twelve characters with a total of 27 character states were used in this analysis foll owing Kimbel and Rak (1993) (Table 2). When scoring characters, consistency with Kimbel and Rak's definitions was attempted. However, many of their character states are ambiguous. Thus a thorough exposition of character and character state definitions is necessary.

Character 1: Inclination of the tympanic. This character describes the orientation of the tympanic plate. Kimbel and Rak (1993) define the states for this character as horizontal, inclined, and vertical with no distinct definition for each category. Although such unclear definitions are practical when thereare clear clusters of morphologies, they are difficult to apply when a morphology has continuous variation. As shown in Figure 1, when this character is treated as an angle between the middle portion of the tympanic plate and a transverse plane, no clear categories of inclination are apparent and certainly none that 
TABLE 2. Character and character state definitions ${ }^{1}$

\begin{tabular}{|c|c|}
\hline Character & State \\
\hline 1. Inclination of the tym- & 0: Horizontal $\left(0^{\circ}-30^{\circ}\right)$ \\
\hline $\begin{array}{l}\text { panic plate relative to } \\
\text { the occlusal plane }\end{array}$ & 1: Inclined $\left(30.1^{\circ}-60^{\circ}\right)$ \\
\hline $\begin{array}{l}\text { the occlusal plane } \\
\text { 2. Relationship of the }\end{array}$ & 2: Vertical $\left(60.1^{\circ}-90+{ }^{\circ}\right)$ \\
\hline 2. Relationship of the & $\begin{array}{l}\text { 0: PGP lies anterior } \\
\text { 1: PGP merges with the }\end{array}$ \\
\hline $\begin{array}{l}\text { postglenoid process } \\
\text { (PGP) to the tympanic }\end{array}$ & $\begin{array}{l}\text { 1: PGP merges with the } \\
\text { tympanic superiorly }\end{array}$ \\
\hline \multirow[t]{2}{*}{ 3. PGP size } & $0:$ Large \\
\hline & $\begin{array}{l}\text { 1: Reduced or completely } \\
\text { merged with the tym- } \\
\text { panic plate }\end{array}$ \\
\hline \multirow[t]{3}{*}{ 4. Petrous crest } & 0 : Absent \\
\hline & 1: Weak \\
\hline & $\begin{array}{l}\text { 2: Moderate } \\
\text { 3: Strong }\end{array}$ \\
\hline 5. Vaginal process & 0 : Absent \\
\hline \multirow{2}{*}{ 6. Mastoid fissure } & 1: Present \\
\hline & $\begin{array}{l}\text { 0: Open laterally } \\
\text { 1: Closed laterally }\end{array}$ \\
\hline \multirow{2}{*}{$\begin{array}{l}\text { 7. Orientation of petrous } \\
\text { relative to the sagittal } \\
\text { plane }\end{array}$} & $0:$ More sagittally oriented \\
\hline & 1: More coronally oriented \\
\hline \multirow[t]{2}{*}{ 8. Preglenoid plane } & 0: Horizontal and extensive \\
\hline & $\begin{array}{l}\text { 1: Vertical or very inclined } \\
\text { and restricted }\end{array}$ \\
\hline \multirow{2}{*}{$\begin{array}{l}\text { 9. Relationship of the } \\
\text { foramen ovale (FO) to } \\
\text { the lateral pterygoid } \\
\text { plate (LPP) }\end{array}$} & $0:$ FO indents LPP \\
\hline & 1: FO lies posterior to $\mathrm{L}$ \\
\hline \multirow{3}{*}{$\begin{array}{l}\text { 10. LPP shape when } \\
\text { viewed laterally }\end{array}$} & 0: Triangular; long base, \\
\hline & superiorly \\
\hline & $\begin{array}{l}\text { 1: Rectangular or irregular; } \\
\text { abbreviated base }\end{array}$ \\
\hline 11. Eustachian process & 0 : Absent \\
\hline & \\
\hline \multirow{3}{*}{$\begin{array}{l}\text { 12. Orientation of the } \\
\text { medial aspect of the } \\
\text { tympanic plate (not } \\
\text { including Eustachian } \\
\text { process) }\end{array}$} & $\begin{array}{l}\text { 0: Faces inferiorly } \\
\text { 1. Faces anteroinferic }\end{array}$ \\
\hline & 1: r aces anteroinferıorly \\
\hline & \\
\hline
\end{tabular}

${ }^{1}$ See text for detailed character state definitions.

distinguish taxa. The middle portion of the tympanic is defined here as lying between parasagittal lines drawn through the entoglenoid process, laterally, and the postglenoid process, medially. In this study, the states for character 1 were arbitrarily defined as 0 -horizontal $\left(0^{\circ}-30^{\circ}\right)$, 1 -inclined $\left(30.1^{\circ}-60^{\circ}\right)$, and 2 -vertical $\left(60.1^{\circ}-90^{\circ}+\right)$ (Table 2).

For all of the pongid specimens and a portion of the hominids, the occlusal plane was used as the transverse plane for measurement of tympanic inclination. For some of the hominids, the occlusal plane had to be approximated from either preserved dentition or from the alveolar plane. Furthermore, all of the hominids and a representative sample of pongids $(\mathrm{N}=12)$ wereseriated

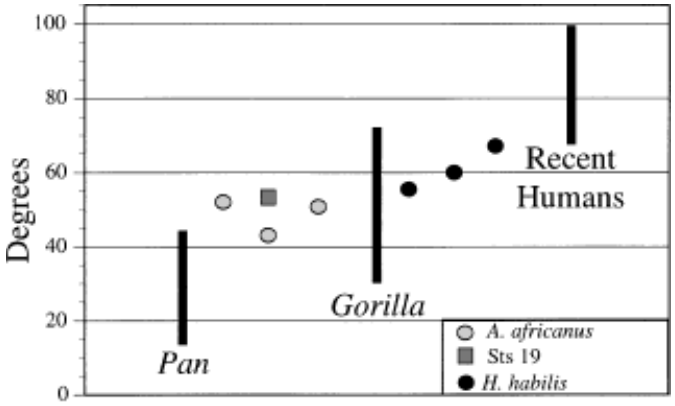

Fig. 1. Sample ranges and individual hominid plots for deviation of the tympanic plate from the occlusal plane (in degrees). When character 1 is treated as a continuous metric variable, no clear divisions into character states are evident nor are there distinct separations between taxa. The recent human sample consists of five recent Filipino crania and two recent I nuit crania from the collections of the Paleoanthropology Laboratory, University of Michigan.

for tympanic inclination. For the seriation, specimens were aligned with each other based upon structures surrounding the tympanic (e.g., external auditory meatus, entoglenoid process, posterior zygomatic process, posterior maxillary margins) as well as the occlusal and alveolar planes. In this manner, the isolated glenoid specimens KNM-ER 3891 and $\mathrm{OH} 13$ could be effectively scored since both clearly clustered with other specimens. The specimen in question, Sts 19, preserves only most of the left $\mathrm{M}^{3}$ with a limited portion of alveolus. Thus, measurement of the tympanic angle was only approximated. However, this combined with Sts 19's placement in the seriation clearly demarcates it as having an inclined tympanic, state 1.

Character 2: Relation of the postglenoid process to the tympanic plate. As defined by Kimbel and Rak (1993), the states for this character are 0-the postglenoid process (PGP) lies anterior to the tympanic, and 1-the PGP merges with the tympanic superiorly. Variation within the pongids was actually greater than allowed for by these distinctions. Four variations were originally identified in this study: 1) the PGP lies completely anterior to the tympanic, separated by a groove, the recessus fossae mandibulae (e.g., Sts 5); 2) the PGP is separated superomedially and laterally from the tym- 
panic but joins with it centrally (e.g., many of the pongids); 3) the PGP is separated superolaterally from the tympanic but joins with the tympanic superomedially (e.g., Sts 19, MLD 37/38); and 4) the PGP is completely part of the tympanic plate, although the squamotympanic fissure may be observable (e.g., most recent humans and SK 847). In order to remain consistent with Kimbel and Rak's scoring, the specimens with the latter two variations were scored as having a PGP that merges superiorly with the tympanic (state 1), while specimens exhibiting either of the first two variations were assigned to state 0, PGP anterior to the tympanic.

Character 3: Postglenoid process size. When comparing anatomical structures, size differences can be difficult to delineate into categories. Morefundamental than the problem of having to demarcate character state boundaries for something that possibly has continuous variation is the difficulty in defining what exactly is meant by "size" itself. Postglenoid process anteroposterior, mediolateral, and inferosuperior dimensions all vary between individuals and between taxa. These dimensions vary on the same process since the structure is not rectangular in shape. Furthermore, gross comparisons of structural size do not account for variations in body size.

In this study, size was represented as the inferior projection of the postglenoid process relative to the inferior projections of the preglenoid plane, the external auditory meatus and the tympanic. Viewed in normal lateralis, five variations were originally delineated among the pongid samples and a small sample of recent Filipino crania $(\mathrm{N}=10): 1$ ) the PGP projects below the inferolateral margin of the tympanic, 2) the PGP projects below the external auditory meatus but not inferior to the inferolateral margin of the tympanic, 3) the PGP projects below the level of the articular tubercle but not below the auditory meatus, 4) the PGP does not project below the level of the articular tubercle, and 5) the PGP is either absent or is indistinguishable from the tympanic plate. The first three of these variations were collapsed into the "large PGP" charac- ter state used by Kimbel and Rak (1993), while the last two were collapsed into their "reduced postglenoid process" character state.

\section{Character 4: Petrous crest development.} The petrous crest forms the inferior margin of the tympanic plate. As discussed with character 5, petrous crest and vaginal process development are closely linked. Although this association may justify collapsing them into a single character, the two were left separate in order to be consistent with Kimbel and Rak's (1993) methodology.

According to Weidenreich (1943), all of the large-bodied apes exhibit petrous crests, although Kimbel and Rak (1993) report that Pan and Gorilla lack such a structure. Both petrous crests and the vaginal process portion of the petrous crest were observed on the African pongids examined in this study. Asidefrom size differences, the petrous crests of African pongids examined in this study varied in the following ways: 1) no crest-like development of the inferior tympanic margin (most common in Pan), 2) a petrous crest that is either uniform in size or only gradually increases in size from lateral to medial, 3) a petrous crest that exhibits an enlargement anterior to the apparent styloid pit, and 4) no petrous crest development other than that seen just anterior to thestyloid pit.

Of the specimens assigned to $A$. africanus, Sts 19 and Sts 5 clearly possess petrous crests that begin laterally at a point just medial to their mastoid processes. The left inferior tympanic margin of Sts 5 appears to be eroded away, while only the lateral portion of the right petrous crest is preserved. The right petrous crest of Sts 5 increases in size from lateral to medial and at the point of its medial break is indistinguishable from that possessed by Sts 19 at that point. On Sts 19 , the crest continues medially as an enlarged lip that lies anterior to the styloid pit. This enlarged portion of the petrous crest is slightly concave on its posterior surface. MLD 37/38 lacks a petrous crest except a small, rounded crest that forms the anterior margin of the styloid pit. Stw 505 exhibits a particularly rugose petrous crest, but lacks any enlargement in the region of thestyloid pit. 
For petrous crest development, four states were used: 0-absent, 1-weak, 2-moderate, and 3-strong. Specimens, such as MLD $37 / 38$, whose crest devel opment was li mited to the styloi d region were scored as lacking a petrous crest. Specimens with posteroinferiorly rounded-off tympanics were al so scored as lacking petrous crests. Hominid specimens that exhibited a petrous crest were seriated by overall size and rugosity and divided into states 1 through 3 . The pongids were then placed within this seriation relative to the morphologies exhibited by the hominids.

Character 5: Thevaginal process. There appears to be much disagreement over an exact definition of the vaginal process. Wolpoff (1996:444) refers to it as a "small projecting open cylinder. Inside it rests a long spur of bone called the styloid process." According to Schwartz (1995:66): "On the other side of the styloid process is another crest of bonethe vaginal process-which appears to diverge from the crestlike edge of the external acoustic meatus."

In the Sinanthropus cranial monograph, Weidenreich clearly recognizes the vaginal process as a transformation of a portion of the petrous crest in response to the presence of the styloid process:

In modern man the (styloid) process rises behind the free border of the tympanic plate and presses it forward. In numerous cases the plate itself grows thicker where the process leans against it, and produces irregular projections which more or less surround the process, particularly on the medial side. This transformation of the tympanic plate has been termed "vagina processus styloidei." (1943:59)

This definition of the vaginal process, "irregular projections that more or less surround the process" (emphasis added), is the definition that he has in mind when he states, "Ther efore, even if a styloid process is developed in anthropoids, in no instance does it come into close connection with the crista petrosa nor is the latter transformed into a vagina as is true in man" (Weidenreich, 1943:59). That the styloid process is present, al beit frequently unfused, among the great apes has most recently been established by Dean (1984). Contrary to Weidenreich, the styloid pits of many of the pongids examined in this present study lay close in association with the petrous crest. Gorillas and, according to Weidenreich (1951), the Ngandong and Zhoukoudian crania exhibit strong "spinae crista petrosa" that lie in close association with the styloid pit. This spine bears an indentation on its posterolateral surface for the passage of the styloid process. Thus, the petrosal spine appears to be an elaborated vaginal process, although it does not fully envel ope the base of the styloid process or the styloid pit. If such envelopment is used to identify the vaginal process, then not a single pongid, $\mathrm{A}$. africanus specimen, or Sts 19 possesses a vaginal process. Sts 19 merely exhibits an enlargement of the petrous crest anterior to the styloid pit with a slight concavity on its posterior surface. In this study, the only specimen that comes close to exhibiting a transformation of the petrous crest that surrounds the styloid process is Stw 53. Since Kimbel and Rak scored Sts 19 and all of the Homo specimens as having vaginal processes, they clearly did not use Weidenreich's (1943) definition.

Definitional confusions aside, Sts 19's condition was used as the model for exhibiting a vaginal process in order to remain consistent with Kimbel and Rak's (1993) scoring of the specimen for this character. As on Sts 19, an enlargement of the petrous crest, either with or without a clear posterior concavity and in clear association with the styloid pit, was found among the pongid specimens and on at least one of the $A$. africanus specimens, MLD 37/38. MLD 37/38 lacks a petrous crest except a small, rounded crest that forms the anterior margin of the styloid pit. It is this cresting that is here identified as a vaginal process. That such a structure was present on Sts 5 is indicated by the fact that at its medial break, the right petrous crest of Sts 5 is as developed as and is otherwise similar to that exhibited by Sts 19. The left side is too eroded to exhibit such anatomy. Stw 505 exhibits a petrous crest that is enlarged for its entire length, including the portion lying anterior to thestyloid pit. No other A. africanus specimens available for study preserved this anatomy. Among the $\mathrm{H}$. habilis sample, the three specimens that preserve this region all exhibit vaginal processes. $\mathrm{OH} 24$ possesses one similar to Sts 19. SK 847 ex- 
hibits a slight enlargement of the petrous crest anterior to the styloid pit. Although this makes it superficially like Sts 19 , the extremely vertical nature of the tympanic and the thinness of the petrous crest make SK 847 clearly different from the Sterkfontein specimen. As stated above, Stw 53's vaginal process is the most enveloping of all of the specimens in this study.

For character 5 , vaginal process presence or absence, all specimens that exhibited an enlargement of the petrous crest at the styloid region (e.g., Sts 19), petrous crests that were limited to the styloid region (e.g., MLD 37/38), or transformations of the petrous crest that enveloped the base of the styloid (e.g., Stw 53) were scored as possessing vaginal processes (state 1 ). An enlargement of the petrous crest limited to the styloid region and a petrous crest that is limited to the styl oid region are posited here as homol ogous structures formed in reaction to the same functional requirements. Specimens that preserved the styloid region but lacked any of the above three criteria were scored as lacking vaginal processes (state 0 ).

Character 6: The mastoid fissure. This character describes whether or not the petrous crest and the mastoid connect laterally so as to prohibit a lateral extension of the mastoid fissure behind the external auditory meatus. Three primary variations were originally identified among the pongid and hominid samples in this study: 1) the mastoid fissure extends superolaterally as a groove until directly posterior to the external auditory meatus (e.g., most of the pongids); 2) the mastoid fissure is partially open laterally and does not extend superiorly behind the external auditory meatus (e.g., Sts 5); and 3) the mastoid fissure is closed laterally by the petrous crest which closes with the mastoid process rather than continuing with the path of the tympanic (e.g., Sts 19). Following the two states used by Kimbel and Rak (1993), the first two variations were collapsed into character state 0 , mastoid fissure open laterally, while the last variation was recognized as character state 1, mastoid fissure cl osed laterally.
Character 7: Orientation of the petrous portion of the temporal. Two character states were recognized in this study and in that of Kimbel and Rak (1993). Compared to living African apes, modern humans have a petrosal pyramid that is more coronally oriented. Pongids exhibit petrosals that are sharply bent at or near the carotid foramen (Weidenreich, 1943). The portion of the petrosal superior and posterior to the tympanic in apes is oriented much more coronally than the comparable section in modern humans. The petrous pyramid of apes is sharply bent away from the posterolateral petrosal and runs almost parallel to the sagittal plane (Weidenreich, 1943). Rather than defining the orientation of the pyramid portion relative to the rest of the petrous, character 7 demarcates the divergence of the pyramid portion alone from the sagittal plane. Kimbel and Rak (1993) do not define exactly what portion of thepetrosal they are discussing. However, the scoring that they provide indicates that they are referring to the pyramidal portion. They report that all of their pongids exhibited sagittally oriented petrosals.

The angle formed by the juncture of the sagittal plane and a line drawn through the carotid foramen and the pyramidal apex was measured on a subset of the pongids and all of the measurable hominid specimens. Summary statistics are given in Table 3. The angle of the only $\mathrm{H}$. habilis specimen that was measurable, Stw 53, was used to demarcate the "more coronal ly oriented" category, character state 1 . Specimens exhibiting more acute angles were categorized as having "sagittally oriented" petrous pyramids, character state 0 . A plastic jig demarcating the boundary between sagittal and coronal orientations was used to score the pongids that were not measured directly.

Character 8: The preglenoid plane. This character describes the morphology of the preglenoid plane. Specimens clustered into three distinct groups: pongids (very extensive and horizontal), A. africanus and Sts 19 (moderately horizontal and extensive), and the $\mathrm{H}$. habilis specimens (steep and restricted). Following Kimbel and Rak (1993), two character states were recognized. The first two variations were col- 
TABLE 3. Orientation of the petrous pyramid relative to the sagittal plane: Summary statistics ${ }^{1}$

\begin{tabular}{llrr}
\hline \multicolumn{1}{c}{ Sample } & Mean (SD) & N & C.V. \\
\hline Gorilla gorilla & $22.9^{\circ}\left(3.6^{\circ}\right)$ & 11 & 15.57 \\
Pan trogl odytes & $19.4^{\circ}\left(2.5^{\circ}\right)$ & 17 & 12.87 \\
Australopithecus africanus & $33.3^{\circ}\left(2.9^{\circ}\right)$ & 2 & 7.44 \\
Austral opithecus africanus & & & \\
$\quad$ with Sts 19 & $34.5^{\circ}\left(2.8^{\circ}\right)$ & 3 & 8.069 \\
Sts 19 & $37^{\circ}$ & - & \\
Homo habilis (Stw 53) & $36^{\circ}$ & - & - \\
Homo habilis with Sts 19 & $36.5^{\circ}(0.707)$ & 2 & 1.937 \\
\hline
\end{tabular}

1 Measurement of the angle between the sagittal plane and a line drawn through the carotid foramen and the apex of the petrous.

lapsed into character state 0 , the preglenoid plane is horizontal and extensive, while the habiline variation was assigned state 1 , the preglenoid plane is restricted anteroposteriorly and is steep.

Character 9: Relationship of the foramen ovale to the lateral pterygoid pro cess. The states for this character as provided by Kimbel and Rak (1993) are not mutually exclusive, and were thus difficult to apply. The two states are: 0-foramen ovale indents the lateral pterygoid plate, and 1-foramen ovale lies posterior to the lateral pterygoid. In some specimens examined in this study, the foramen oval eindents the posterior lip of the lateral pterygoid plate. Thus the foramen is both behind the plate and is indenting it. Such an enigmatic condition is present on Sts 19. In order to remain consistent with Kimbel and Rak's (1993) scoring of this specimen, its morphology served as the baseline for scoring the foramen ovale as posterior to the lateral pterygoid plate (state 0 ).

Character 10: Shape of thelateral pterygoid plate. Three variations were originally discerned among the pongids and hominids in this study: 1) the lateral pterygoid process (LPP) is triangular in shape in norma lateralis and exhibits a long base, superiorly; 2) the LPP is irregular in shape with a semi-abbreviated base, superiorly; and 3 ) the LPP is rectangular or irregular in shape with an abbreviated base, superiorly. The last two variations were collapsed into character state 1 , while the first variation was classified as state 0 .

Scoring the hominid specimens for this character was particularly difficult, since none of them preserve an intact lateral pterygoid plate. The middle one-third of the posterior lateral pterygoid plate margin of Sts 19 is broken away. Without this portion, it is not readily possible to describe its overall shape. Of the hominids used in this study, Sts 5 and SK 847 best preserve the lateral pterygoid plate. SK 847 clearly exhibits a plate that has an anteroposteriorly short superior margin, and whose lower two-thirds are mostly rectangular in shape. Sts 5 exhibits clearly a triangular shaped plate with a relatively long base, superiorly. Using these two hominids as models, the pongids and other hominids were scored as effectively as possible.

Character 11: The Eustachian process. When present, this structure forms the anteromedial-most point of thetympanic plate. Its name was coined by Owen (1851) in his description of osteological anatomy of the chimpanzee, although it has been labeled the "processes styliformes" by Van der Klaauw (in Weidenreich, 1951), the "processus supratubalis" (Weidenreich, 1943:61), and the "processus infratubarius" (Weidenreich, 1951:276). Dean (1985) provides a review of the debate over this structure's function.

Unlike most of the other characters, this character's states could not reasonably be modeled after its condition on Sts 19 as reported by Kimbel and Rak (1993). Kimbel and Rak (1993) report that Sts 19 does not possess a Eustachian process, although it does possess an analogous structure. According to Kimbel and Rak's (1993) scoring, the process exhibited by A. africanus (except Sts 19) is not homologous to the similar structure as seen in hominoids, many Homo specimens (Weidenreich, 1943, 1951), and most other mammals (Cave, 1979). However, Broom and Robinson (1950) dearly describe the same process on Sts 19 as exists on Sts 5, Pan basicrania, and recent humans. On Sts 5: "In front of the carotid foramen there is a well developed process passing, from the front side of the petrosal, downwards, forwards and inwards. This apparently is for the attachment of the levator palati muscle" (Broom and Robinson, 1950: 21). On Sts 19: "There is a bony process 
apparently for the levator palati. The condition is al most exactly as seen in an Australian skull we have. But the condition is also not unlike that seen in some chimpanzees" (Broom and Robinson, 1950:30). More re cently, Dean (1985) dissected the muscular attachments of the process and concluded that great apes, MLD 37/38, and Sts 5 closely resemble each other in this respect. According to Weidenreich $(1943,1951)$, the Eustachian process is found among both the Zhoukoudian and Ngandong crania and "is a characteristic formation in anthropoids ... where it attains considerable dimensions" (1943:61). Furthermore, according to Aiello and Dean (1990:70): “Two club-like Eustachian processes, similar to those typical of African apes and not present on human crania, are also prominent in Sts 5, MLD 37/38 (as well as on the cranium of TM 1517 the type specimen of $\mathrm{P}$. robustus and $\mathrm{H}$. erectus described by Weidenreich [1943])." Finally and most recently, Strait and colleagues (1997) score Sts 19 as possessing a Eustachian process.

In addition to the vast literature support for homology of Eustachian process structure among all pongids and hominids, the following have been discerned in this study: 1) although Sts 19's Eustachian process is significantly smaller, it appears remarkably similar in form and location to that seen in other A. africanus specimens; 2) almost exact matches for both MLD 37/38's and Taung's cone-likeE ustachian processes were found among chimpanzee crania examined in this study; and 3) some male gorillas examined in this studied exhibited Eustachian processes that were almost as large and columnar as those of Sts 5. Because of the similarities in structure, the Eustachian process should be considered homologous among all hominoid taxa that exhibit it.

Character 12: Orientation of the medial aspect of the tympanic plate. This character describes the orientation of the anteromedial-most one-third of the tympanic plate, when viewed in norma lateralis. In order to keep this character independent from character 11, the Eustachian process was not included as contributing to the orientation of the medial tympanic. Without this exclu- sion of the Eustachian process profile when scoring, all of the specimens with large, observable in norma lateralis, Eustachian processes would be scored as having medial tympanics that face inferiorly. Following Kimbel and Rak (1993), two states were identified for this character: 0-the medial tympanic plate faces inferiorly, and 1-the medial tympanic plate faces anteroinferiorly.

\section{Methods of analysis}

Two major issues are relevant in this study. First is the question of whether or not all of the characters and character states employed by Kimbel and Rak (1993) and in this study are valid for testing taxonomic hypotheses. Second is the issue of whether the distribution of character states among the samples falsifies the hypothesis that Sts 19 can be accommodated within the A. africanus hypodigm. Both issues were addressed using the collected character state data.

In addition to the ambiguity of some character definitions noted in the above section, the validity of the characters for systematic analysis was analyzed in terms of 1) character state covariance with sex and 2) intercharacter dependence. We must "avoid confusing gender- and age-related characters with interspecific differences" (Kimbel and Rak, 1993:470). If such characters are used in a taxonomic analysis, it is possible that different sexes and different ages would be classified as separate species. Therefore, in order to be a valid reflection of interspecific differences a character must be independent of sex and age. Using the pongid data, all polymorphic characters were tested for significant dependence on sex with paired chisquare tests. Age-character covariance was not tested since all hominid and pongid specimens used in this study were adult. Paired chi-square tests were also used to test for pairs of characters that significantly covaried with each other. Characters used in a taxonomic analysis should be independent of each other (Le Gros Clark, 1964). Sinceall of the characters used are restricted to the glenoid region it is conceivable that some may vary with each other. The methods applied here only provide preli iminary indications of possible character interdependence and character-sex covariance. Thorough tests 
of character interdependence and charactersex covariance require an evaluation of the ontogeny and functional morphology of the characters of interest. Such an analysis is beyond the scope of this paper.

The probability of falsely significant re sults (Type I errors) increases with the number of tests performed. Therefore, the probability of $r$ number of Type I errors was calculated for both the sex-character and character-character test results. The equation implemented was:

$$
\begin{aligned}
& P(\geq r)=1-\left\{\left(\begin{array}{l}
n \\
0
\end{array}\right)(\alpha)^{0}(1-\alpha)^{n}\right] \\
& \left.\quad+\left[\left(\begin{array}{l}
n \\
1
\end{array}\right)(\alpha)^{1}(1-\alpha)^{n-1}\right]+\cdots\left[\left(\begin{array}{l}
n \\
i
\end{array}\right)(\alpha)^{i}(1-\alpha)^{n-i}\right]\right\}
\end{aligned}
$$

where $\mathrm{n}$ is the total number of tests performed, $r$ is the number of falsely significant tests in $n$ number of tests, $i=r-1$, and $\alpha$ is probability of a falsely significant result for a single test.

The distribution of character states among the samples was used to address the hypothesis that Sts 19 can be accommodated within A. africanus. According to Kimbel and Rak, two lines of evidence indicate that Sts 19 represents a separate species from the other specimens traditionally assigned to $A$. africanus. First, including Sts 19 in A. africanus results in an unacceptably high degree of heteromorphy. Second, Sts 19 shares basicranial apomorphies and plesiomorphies with Homo to the exclusion of $A$. africanus.

In this study the degree of polymorphism was measured and compared for all of the samples in an attempt to replicate Kimbel and Rak's (1993) first finding. A character is polymorphic for a sample/taxon when more than one of its states is expressed. In this study, polymorphism among the taxa was examined in two primary ways. First, the total number of polymorphism among the taxa was examined in two ways. First, the total number of polymorphic characters per sample was tabulated. That is to say, if a sample exhibited two characters that each exhibited more than one character state, then that sample was characterized by two polymorphic characters. Thetotal number of polymor phic characters was compared among the samples, with special attention paid to how A. africanus induding Sts 19 compared with thetwo extant pongid samples.
This study also examined differences in polymorphism between groups on a character by character basis. For example, the number of character states for character 1 exhibited by $A$. africanus with Sts 19 included was compared to the number of states for this character exhibited by A. africanus without Sts 19, P. trogl odytes, G. gorilla, H. habilis with Sts 19 included, and $\mathrm{H}$. habilis without Sts 19.

Although a pattern of polymorphism may be sufficient to falsify a single species hypothesis, an unusually high degree of polymorphism cannot falsify a single species hypothesis on its own. A high level of polymorphism in a fossil sample may be suggestive of the presence of multiple species, but does not conclusively indicate that multiple species are represented, even if that level of polymorphism is higher than that seen in any living taxon. As Kelly (1993) has demonstrated, some extinct species encompassed ranges of variation greater than that seen in their living rel atives. Using the degree of polymorphism of extant taxa as a guide for the maximum range of variation in species would have incorrectly falsified the single species hypothesis in the case discussed by Kelly (1993), and there is no reason to believe that it would not in other circumstances as well.

In an attempt to replicate Kimbel and Rak's (1993) second finding, character state distributions among the samples, using the pongids as the outgroup, were examined in order to determine character state polarity. If a state was present in the outgroup it was assumed plesi omorphic. When actual operational taxonomic units, as opposed to single specimens, are used in phylogenetic analysis it is possible, although undesirable (e.g., Maddison and Maddison, 1992; Nixon and Wheeler, 1990), to treat ancestral polymorphism as a state in its own right. In this manner, two terminal taxa that share a state and are monomorphic for that state can be seen as uniquely linked through common ancestry. However, since this study deals with a single specimen (which, by definition, cannot be polymorphic) polymorphism was not coded as a state separate from its constituent states. The taxonomic affinity of Sts 19 was assessed in terms of 
TABLE 4. Character-sex covariance: Relationship of the po stglenoid process to thetympanic plate (character 2$)^{1}$

\begin{tabular}{lccc}
\hline & Male & Female & Totals \\
\hline $\begin{array}{c}\text { PGP lies ante } \\
\text { rior (state 0) }\end{array}$ & $\begin{array}{c}\text { 40 (15 Gorilla } \\
\text { 25 Pan) }\end{array}$ & $\begin{array}{c}\text { 30 (11 Gorilla } \\
\text { 19 Pan) }\end{array}$ & 70 \\
$\begin{array}{l}\text { PGP merges } \\
\text { with tym- }\end{array}$ & 5 (4 Gorilla 1 & 11 (9 Gorilla 2 & 16 \\
$\begin{array}{l}\text { panic (state 1) } \\
\text { Totals }\end{array}$ & 45 & Pan) & \\
\hline
\end{tabular}

${ }^{1}$ Pongids only. Character 2 significantly covaries with sex $\left(\chi^{2}=3.5, P=.0614\right)$.

the synapomorphies and symplesiomorphies with the outgroup pongid and hominid samples. A pattern of synapomorphies with $H$. habilis to the exclusion of $A$. africanus or a pattern of apomorphic states aligning all of the A. africanus to the exclusion of Sts 19 would have been considered valid falsifications of the single species hypothesis.

\section{RESULTS}

\section{Character-sex dependence}

Two characters were found to vary significantly with sex: relationship of the postglenoid process to the tympanic plate (character 2) and shape of the lateral pterygoid plate (character 10). For character 2, more female than male pongids possess postgle noid processes that merge superiorly with the tympanic plate (Table 4). However, the significance of this dependence is not terribly high $\left(\chi^{2}=3.5, P=.0614\right)$. The sexual dimorphism for character 10 (Table 5 ) is slightly more apparent and significant $\left(\chi^{2}=4.06, P=.044\right)$. Female pongids tend to have triangular, broad based lateral pterygoid plates, while males tend to have more irregularly shaped, abbreviated based lateral pterygoid plates (Fig. 3). However, the probability that both results are falsely significant is high $(45.76 \%$, number of tests $=10, .90$ confidence level). Thus, it is unlikely that there is significant character covariance with sex.

\section{Intercharacter dependence}

A total of five pairs of characters were found to significantly covary. They are listed in Table 6. The probability that all of the significant results are Type I errors is $7.29 \%$ (total number of tests $=45 ; .95$ confidence level). Thus it is likely that at least some
TABLE 5. Character-sex covariance: Lateral pterygoid plate shape (character 10) ${ }^{1}$

\begin{tabular}{cccc}
\hline & Male & Female & Totals \\
\hline $\begin{array}{c}\text { LPP triangular } \\
\text { with long } \\
\text { base(state 0) }\end{array}$ & $\begin{array}{c}\text { 15(9 Gorilla 6 } \\
\text { Pan) }\end{array}$ & $\begin{array}{c}\text { 23 (13 Gorilla } \\
\text { 10 Pan) }\end{array}$ & 38 \\
$\begin{array}{c}\text { LPP rectan- } \\
\text { gular or }\end{array}$ & $\begin{array}{c}\text { 30 (10 Gorilla } \\
\text { 20 Pan) }\end{array}$ & $\begin{array}{c}\text { 19 (7 Gorilla 12 } \\
\text { Pan) }\end{array}$ & 49 \\
$\begin{array}{c}\text { irregular } \\
\text { (state 1) }\end{array}$ & & & \\
Totals & 45 & 42 & 87 \\
\hline
\end{tabular}

${ }^{1}$ Pongids only. Character 10 significantly covaries with sex $\left(\chi^{2}=4.06, P=.044\right)$.

TABLE 6. Significantly dependent character pairs: Chi-square results

\begin{tabular}{lccc}
\hline Character pair & DF & $\chi^{2}$ & $P$ \\
\hline $\begin{array}{l}\text { Inclination of the tympanic (1) and } \\
\text { relationship of the postglenoid pro- }\end{array}$ & & & \\
$\begin{array}{c}\text { cess to the tympanic (2) } \\
\text { Inclination of the tympanic (1) and } \\
\text { vaginal process expression (5) }\end{array}$ & 2 & 8.83 & 0.012 \\
$\begin{array}{l}\text { Inclination of the tympanic (1) and } \\
\text { orientation of the medial tympanic } \\
\quad(12)\end{array}$ & 2 & 6.46 & 0.024 \\
$\begin{array}{l}\text { Relationship of the postglenoid pro- } \\
\text { cess to the tympanic(2) and vaginal } \\
\text { process expression (5) }\end{array}$ & 1 & 6.046 \\
$\begin{array}{l}\text { Vaginal process expression (5) and } \\
\text { lateral pterygoid plate shape (10) }\end{array}$ & 1 & 10.79 & 0.001 \\
\hline
\end{tabular}

intercharacter dependence is present among the set of 12 characters.

It is of interest that three characters in particular significantly covary with others and each other. These are characters 1 , inclination of the tympanic; 2 , relationship of the postglenoid process to the tympanic; and 5 , the vaginal process. It is not surprising that inclination of the tympanic is correlated with the relationship of the postglenoid process. The recent human condition, where the vertical postglenoid process is usually completely merged with the equally vertical tympanic, is illustrative of this interdependence. The interrelationship of vaginal process expression and the inclination of the tympanic is equally apparent. The vaginal process, which envelopes the base of the styloid process, is an extension of the petrous crest (Weidenreich, 1951). Since the petrous crest is an inferior projection of the posteroinferior margin of an inclined tympanic (Weidenreich, 1951), it seems that possession of an inclined tympanic is prerequisite to possession of a vaginal process. Thus it is not surprising that vaginal pro- 
cess expression is also correlated with the relationship of the postglenoid process to the tympanic. The relationship between the inclination of the tympanic and the orientation of its medial aspect is also not surprising given that it is a single ontogenetic structure. However, the significant dependence found between character 5 , the vaginal process, and character 10, shape of the lateral pterygoid plate, is rather enigmatic since the two structures do not lie in close proximity to one another. On a cautionary note, only a thorough analysis of the ontogeny and functional morphol ogy of all of these characters can effectively establish their interdependence.

\section{Polymorphism}

Table 7 gives the distribution of character states among the samples and scores for individual hominid specimens are provided in Appendix B. The degree of polymorphism among the pongids in this study is far greater than that reported by Kimbel and Rak (1993). Among Pan, 10 characters express more than one character state, while among Gorilla nine characters are polymor phic (Fig. 2). A. africanus including Sts 19 exhibits nine polymorphic characters. A. africanus without Sts 19 exhibits only seven polymorphisms. When Sts 19 is included in $\mathrm{H}$. habilis the total number of polymorphic characters increases from seven to eight. Thus, $\mathrm{H}$. habilis with Sts 19 possesses almost as many polymorphic characters as does A. africanus including Sts 19. Furthermore, A. africanus including Sts 19 is less polymorphic than $\mathrm{P}$. trogl odytes.

It does not seem unreasonable that the polymorphism that Sts 19 brings to A. africanus is simply the result of normal intraspecific variation. Given a small sample size, whenever a specimen is excluded, polymorphism in that sample will surely decrease. For example, when Sts 5, the specimen most associated with $A$. africanus, is excluded, the taxon's heteromorphy decreases by two characters (Fig. 3). In terms of the number of polymorphic characters, Sts 5 is as strong of a candidate for exclusion from A. africanus than is Sts 19. Finally, excluding either Stw 505 or Sts 71 decreases the taxon's polymorphism by onecharacter. Yet all three
TABLE 7. Distribution of character states among the samples ${ }^{1,2}$

\begin{tabular}{ccccc}
\hline Character & Pongids & A. africanus & Sts 19 & H. habilis \\
\hline 1 & $0,1,2$ & 1 & 1 & 1,2 \\
& $(0)$ & $(0,1)$ & $(2)$ & $(2)$ \\
2 & 0,1 & 0,1 & 1 & 0,1 \\
& $(0)$ & $(0)$ & $(1)$ & $(1)$ \\
3 & 0,1 & 0,1 & 0 & 0,1 \\
& $(0)$ & $(0)$ & $(0)$ & $(1)$ \\
4 & $0,1,2$ & $0,1,2$ & 2 & 2,3 \\
& $(0)$ & $(1,2)$ & $(3)$ & $(3)$ \\
5 & 0,1 & 1 & 1 & 1 \\
& $(0)$ & $(0)$ & $(1)$ & $(1)$ \\
6 & 0,1 & 0,1 & 1 & 0,1 \\
& $(0)$ & $(0)$ & $(1)$ & $(1)$ \\
7 & 0 & 0 & 1 & 0,1 \\
& $(0)$ & $(0)$ & $(1)$ & $(1)$ \\
8 & 0 & 0 & 0 & 1 \\
& $(0)$ & $(0)$ & $(0)$ & $(1)$ \\
9 & 0,1 & 0 & 1 & 0,1 \\
& $(0)$ & $(0)$ & $(1)$ & $(0,1)$ \\
10 & 0,1 & 0,1 & 1 & 1 \\
& $(0)$ & $(0)$ & $(1)$ & $(1)$ \\
11 & 0,1 & 0,1 & 1 & 1 \\
& $(0)$ & $(1)$ & $(0)$ & $(0)$ \\
12 & 0,1 & 0,1 & 1 & 1 \\
& $(0)$ & $(0)$ & $(0)$ & $(0)$ \\
\hline
\end{tabular}

${ }^{1}$ Character state definitions are given in Table 2 and the Methods section.

2 Character state in parentheses are those reported by Kimbel and Rak (1993). See the Methods and Discussion sections for explanations of differences.

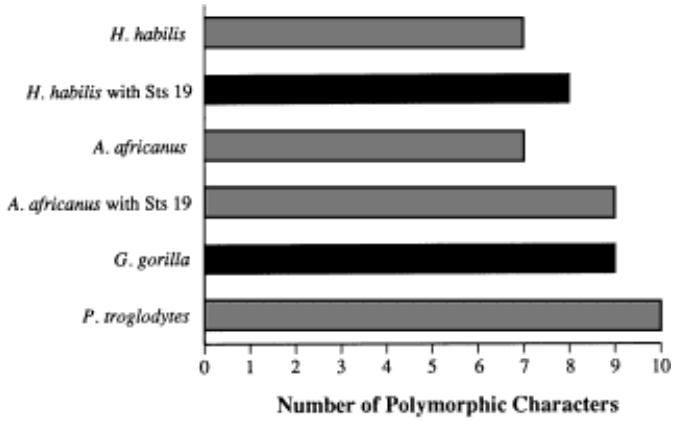

Fig. 2. Degree of polymorphism as measured by the total number of polymorphic characters exhibited by a sample. Note that although including Sts 19 in A. africanus increases that taxon's polymorphism, so does its inclusion in $\mathrm{H}$. habilis.

of these specimens, Sts 5 , Stw 505 , and Sts 71 , are linked to the $A$. africanus hypodigm through shared-derived aspects of facial anatomy as outlined by Rak (1983) and Kimbel and Rak (1993).

When the degree of polymorphism is examined on a character by character basis, it becomes even more clear that $A$. africanus with Sts 19 included is not unusual ly hetero- 


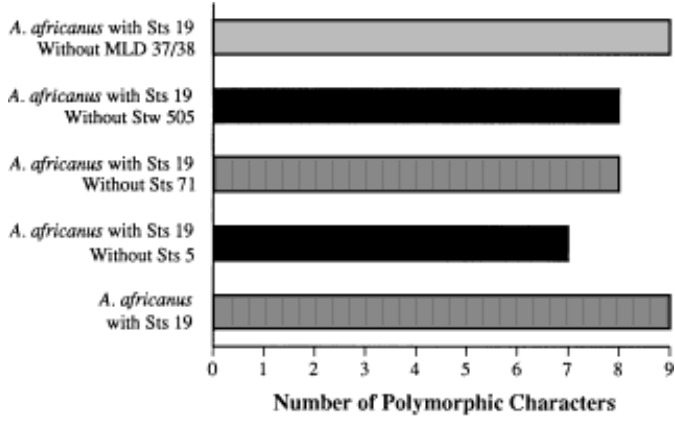

Fig. 3. The number of polymorphic characters (out of a total of 12 characters) for subdivisions of the $A$. africanus sample. All subgroupings include Sts 19.

morphic (Fig. 4). In the case of only one character, orientation of the petrous (character 7), does A. africanus including Sts 19 exhibit more character states than either of the pongid taxa. Furthermore, the pongids exhibit more polymorphism than A. africanus with Sts 19 included for two characters: inclination of thetympanic (character 1) and vaginal process expression (character 5).

\section{Character state polarity}

The high degree of polymorphism among the pongid outgroups renders all of the states of many characters plesiomorphic since the states are all expressed among the pongids. The pongids exhibit all possible character states for the following characters: 1, inclination of the tympanic; 2, relationship of the postglenoid process to the tympanic; 3, size of the postglenoid process; 5, expression of the vaginal process; 6, mastoid fissure morphology; 9, relationship of the foramen ovale to the lateral pterygoid plate; 10, lateral pterygoid plate shape; 11, Eustachian process expression; and 12, orientation of the medial aspect of the tympanic. Thus, all of the character states for these characters are considered plesiomorphic. Among the other three characters, three states are apomorphic relative to the outgroups. Although weak, moderate, and absent petrous crests are found among the pongids, strongly developed petrous crests are not. Thus, character state 3 of character 4 is apomorphic. The pongids are monomorphic for orientation of the petrous (character 4) and preglenoid plane form (character 8).
All of the pongids have a horizontal and extensive preglenoid plane. Thus, restricted and vertical or very inclined preglenoid planes are apomorphic relative to the outgroups. Finally, all pongids exhibit sagittally oriented petrous pyramids and, thus, more coronally oriented ones are apomorphic.

\section{Distribution of apomorphies among the hominids}

With only three apomorphic characters, it is difficult to observeany patterns of congruence among characters that would indicate the taxonomic affinities of Sts 19. F or two of the three characters, both Sts 19 and A. africanus exhibit the plesiomorphic condition, while $\mathrm{H}$. habilis possesses the derived (Table 8). Such a situation, at best, does not address the null hypothesis. Since two or more species may share features through common ancestry, symplesiomorphies cannot define taxa on their own, but they may be suggestive of taxonomic alignment. In this study, both cases of symplesiomorphy indicate that Sts 19 shares affinities with A. africanus and the outgroups, but not with $\mathrm{H}$. habilis. The third character is much more significant. Sts 19 exhi bits the derived condition for petrous orientation (character 7) to the exclusion of $A$. africanus. All of the habiline specimens in this study also exhibited the derived condition: more coronally oriented petrous pyramids. Thus, only one apomorphy aligns Sts 19 with $\mathrm{H}$. habilis.

However, when orientation of the petrous (character 7) is treated as a continuous metric variable, A. africanus with Sts 19 is still far less variable than either of the pongid species (Fig. 5). Table 3 gives coefficients of variation and other summary statistics for petrous orientation among the pongids and A. africanus. Given that Sts 19 deviates little from $A$. africanus in terms of petrous orientation, falsification of thesingle species hypothesis is unwarranted.

\section{DISCUSSION}

The results of this study contrast with those reported by Kimbel and Rak (1993). Using the same characters and character states, a comparable hominid sample, and the same two pongid species, they rejected 


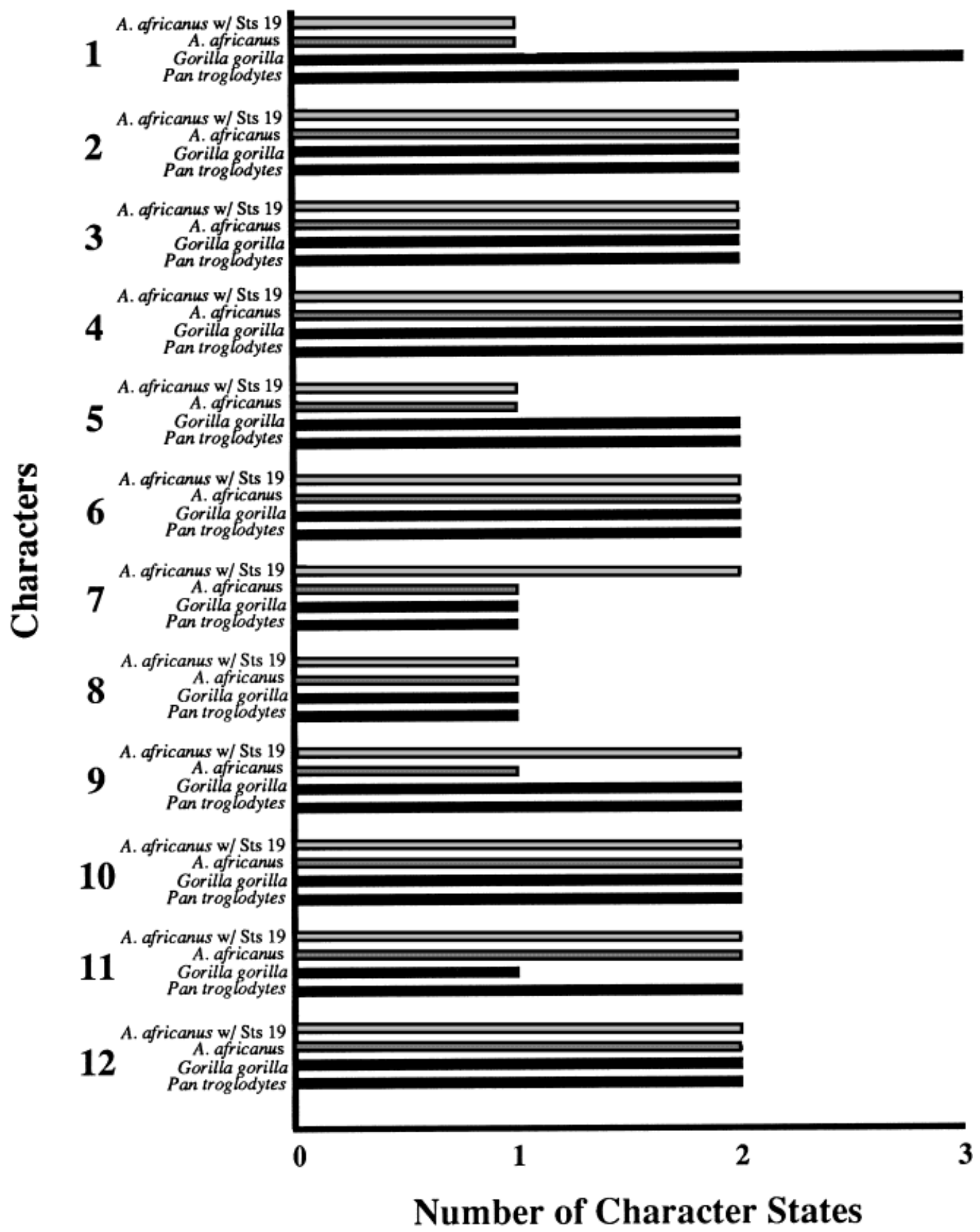

Fig. 4. Degree of polymorphism for each character and for each sample. For only character 7 is $A$. africanus including Sts 19 more polymorphic than either of the pongid taxa. However for characters 2 and 5 the pongid taxa display more character states than does A. africanus including Sts 19. 
TABLE 8. Distribution of apomorphies among the hominids

\begin{tabular}{cllll}
\hline Character & \multicolumn{1}{c}{ Derived state } & A. africanus & Sts 19 & H. habilis \\
\hline 4 & Strong petrous crest & plesiomorphic & plesiomorphic & apomorphic \\
7 & Orientation of the petrous & plesiomorphic & apomorphic & apomorphic \\
8 & Steep and restricted preglenoid plane & plesiomorphic & plesiomorphic & apomorphic \\
\hline
\end{tabular}

${ }^{1}$ Only SK 847 exhibits a strong petrous crest.

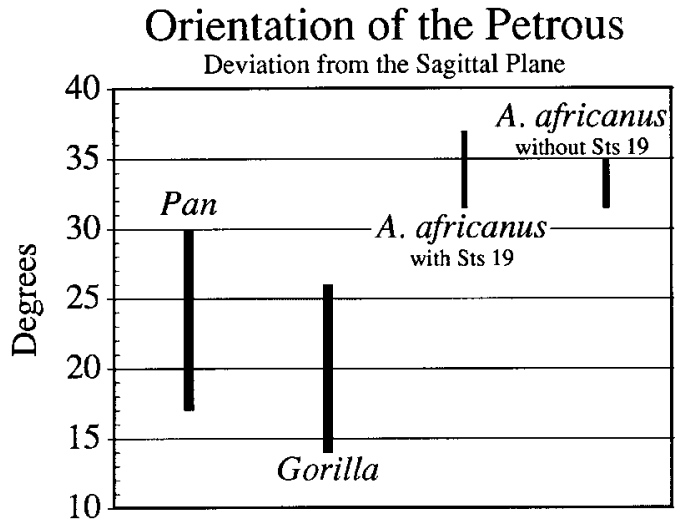

Fig. 5. Sample ranges for deviation of thelong axis of the petrous pyramid from the sagittal plane.

the hypothesis that Sts 19 can be accommodated within A. africanus. Their rejection and this study's inability to reject are not due to different interpretations of the same results. The results differed between these two studies because: 1) pongids in this study exhibited much more polymorphism than those used by Kimbel and Rak's (1993); and 2) the distribution of character states among A. africanus, $\mathrm{H}$. habilis, and Sts 19 differed slightly between the two studies. As discussed below, differences in sample compositions between the two analyses had little, if any, effect upon the differences in results.

\section{Pongid polymorphism}

Only orientation of the petrous (character 7) and preglenoid plane form (character 8) were monomorphic among both of the pongid taxa. Eustachian process expression (character 11) was monomorphic among G. gorilla (it was present on all specimens), but dimorphic among P. trogl odytes. In contrast, Kimbel and Rak (1993) report complete monomorphy among the pongids for all 12 of the characters. Sample consistency may have played a role in this difference. Kimbel and Rak (1993) do not report sample sizes.
TABLE 9. Deviation of the tympanic plate from the occlusal plane: Individual hominid specimen angles and character states

\begin{tabular}{lcc}
\hline Specimen & $\begin{array}{c}\text { Angle } \\
\text { (standard error) }\end{array}$ & $\begin{array}{c}\text { Class } \\
\text { (character state) }\end{array}$ \\
\hline Sts 5 & $42.5(1.041)$ & inclined (1) \\
Stw 505 & $51^{\circ}(2.309)$ & inclined (1) \\
MLD 37/38 & $52^{\circ}(2.646)$ & inclined (1) \\
Sts 19 & $53^{\circ}(2.309)$ & inclined (1) \\
ER 1813 & $54.2^{\circ}(3.245)$ & inclined (1) \\
Stw 53 & $55^{\circ}(1.041)$ & inclined (1) \\
OH 24 & $66^{\circ}(1.000)$ & vertical (2) \\
\hline
\end{tabular}

\section{Differences in the distribution of character states}

For most of the characters, Sts 19's condition, as reported by Kimbel and Rak, was used as the basis from which ambiguous character states were defined. However, for four characters Sts 19 was scored differently. Kimbel and Rak scored Sts 19 as having a vertical tympanic plate (character 1 ), while here it is scored as having an inclined one. Furthermore, they report that all $\mathrm{H}$. habilis specimens have vertical tympanics. I scored Stw 53 and ER 1813 as having inclined tympanic plates and $\mathrm{OH} 24$ as having a vertical tympanic. My delineation of horizontal, inclined, and vertical was based on a division of $90^{\circ}$ into three categories. This also explains why I scored Sts 19 as having an inclined rather than vertical tympanic (contra Kimbel and Rak, 1993). If the "vertical" category's boundary is lowered to accommodate Stw 53, ER 1813, and Sts 19 , it comes within $1^{\circ}$ of including the $A$. africanus specimen MLD 37/38. It seemed to be more reasonable to draw the border between Stw 53 and OH 24 (Fig. 1 and Table 9).

I scored Sts 19 as having a moderate petrous crest (character 4) as opposed to a strong one as reported by Kimbel and Rak (1993). Sts 19's petrous crest is similar in size and robusticity to those of Stw 505, OH 24, ER 3891, and Stw 53. However, the 
crests of all of these specimens are shadowed by the strong petrous crest of SK 847. As discussed above in the Methods section, a hypothesis of homology for the Eustachian process (character 11) as it appears in all hominoid taxa has yet to be fal sified. Thus, I scored Sts 19 as having a Eustachian process (contra Kimbel and Rak, 1993). For orientation of the medial tympanic (character 12), only one hominid, Sts 5, exhibited a medial tympanic that faced truly inferiorly. All other hominids, when compared to Sts 5 and many pongids, have medial tympanic plates that face anteroinferiorly (contra Kimbel and Rak, 1993).

Some characters among A. africanus were scored differently. MLD 37/38, Sts 71, and Stw 505 all have some degree of connection between the postglenoid process and the tympanic plate (character 2). Only Sts 5, which has a tympanic plate posterior to the postglenoid process, fits the pattern described by Kimbel and Rak (1993) for A. africanus. For postglenoid process size (character 3), Sts 71 possesses a reduced process, while Sts 5, MLD 37/38, and Stw 505 have large processes. Sts 71's postglenoid process is not complete: its inferior portion is missing. However, when the preserved portion is compared to other specimens, Sts 71 clearly could not have possessed a postglenoid process larger than the "reduced" processes of KNM-ER 1813 and OH 13. MLD 37/38 possesses an irregularly shaped lateral pterygoid process and thus explains the polymorphism for character 10 , shape of the lateral pterygoid plate.

A possible explanation of the differences in scoring between this study and that of Kimbel and Rak (1993) may be a different approach to assigning character states to a taxon. The lower degree of polymorphism reported by Kimbel and Rak may result from the approach that all states that appear in low frequencies in a species are ignored and not used to characterize the taxon. In this study, if all states that occur among less than $10 \%$ of the pongids are ignored, then characters 3, postglenoid process size, and 6, mastoid fissure morphology, become "monomorphic" among the pongids. However, this does not alter the taxonomic assessment of Sts 19 in this study. Having a reduced postglenoid process (character 3) then becomes apomorphic relative to the outgroups. For this character, however, Sts 19 maintains the plesiomorphic condition, which is also found among $A$. africanus and $\mathrm{H}$. habilis along with the derived state. If all pongids are to be considered as possessing mastoid fissures that are open laterally, then closed mastoi d fissures become apomorphic (character 6). Although Sts 19 does then show the apomorphic condition, so do A. africanus and $\mathrm{H}$. habilis along with the plesiomorphic state. Therefore, even when sample "central tendency" is used as a method of assigning a character state to a taxon, the null hypothesis is unaffected.

\section{Differences in sample compositions}

Including some specimens not used by Kimbel and Rak (1993) only slightly affects the results of my study. The two hominid specimens used here that were excluded by Kimbel and Rak (1993) are Stw 505 and SK 847. Although it is clearly linked to the rest of the A. africanus hypodigm, Stw 505's condition does differ from that of the other $A$. africanus specimens (excluding Sts 19). This specimen exhibits a moderate petrous crest (character 4), while Sts 5 has a weak crest and MLD 37/38 lacks a crest. No other A. africanus specimens used in this study preserve this region well enough to be scored. If Stw 505 is excluded, then moderate petrous crests become autapomorphic for $\mathrm{H}$. habilis as opposed to a synapomorphy of $\mathrm{H}$. habilis and A. africanus. Stw 505 also exhibits the largest cranial capacity of the Sterkfontein sample, yet aspects of its facial anatomy (e.g., strong anterior pillars like Sts 5 and Stw 13, supraorbital form like Sts 5, and relatively tall orbits likeSts 71 ) link it to the A. africanus hypodigm. Stw 505 and Sts 19 are the only specimens attributed to $A$. africanus that exhibit mastoid fissures that are closed laterally (character 6). However, since open and closed lateral mastoid fissures are plesiomorphic, excluding Stw 505 does not result in an additional autapomorphy linking Sts 19 to $\mathrm{H}$. habilis.

Excluding SK 847 from the $\mathrm{H}$. habilis sample reduces the number of polymorphic characters for $\mathrm{H}$. habilis by one, since this specimen possesses the only petrous crest 
scored as strong. This reduction results in the $\mathrm{H}$. habilis sample (excluding Sts 19) having one fewer polymorphic characters as the $A$. africanus sample (without Sts 19). It also reduces the number of polymorphic characters of the H. habilis sample when Sts 19 is included to two steps below that seen in A. africanus when Sts 19 is included. However such changes are largely unimportant given that G. gorilla and P. troglodytes exhibit as much if not more polymorphism than any of the hominid samples.

Possibly more significant than the specimens included are the specimens that were excluded here but were used by Kimbel and Rak (1993). The lack of information about Sts 25 and Stw 266 is especially unfortunate since these $A$. africanus specimens reportedly preserve these regions well (Kimbel, pers. comm.). However, it is difficult to see how these specimens would significantly alter my results. Since I did not find less polymorphism for any character reported by Kimbel and Rak for the A. africanus sample, including Sts 25 and Stw 266 could not have changed the degree of polymorphism results. Furthermore, including these specimens would not apparently affect character state distributions or state polarities. Casts of the temporal regions of $\mathrm{OH} 16$ and KNM-ER 3735 were also not available for study. Yet, in only one case might this have affected the results of this study. If either $\mathrm{OH} 16$ or KNM-ER 3735 lacks an Eustachian process, then including these specimens would have resulted in an additional character state present for this character among the $\mathrm{H}$. habilis sample.

Taung was excluded here because of its juvenile status. However, Rak and colleagues $(1994,1996)$ argue that juveniles can be particularly informative in systematic questions. This is especially the case if they possess autapomorphicstates that characterizetaxon, and thus reinforce theontoge netic depth of that state. The Taung casts available for study preserve only two of the 12 characters clearly. Taung possesses a cone-likeE ustachian process similar in form, but not size, to that exhibited by MLD 37/38. However, such a form is not out of the range of pongid variation as is demonstrated by similar manifestations in some juvenile and adult chimpanzee specimens examined in this study. Taung's petrous pyramid is sagittally oriented like all of the pongids and A. africanus specimens used in this study. Although informative on the ontogeny of some of the morphologies analyzed in this study, Taung's presence or absence from this study does not affect the study's results.

\section{Intraspecific variation and the problem with excluding Sts 19 from $A$. africanus}

The results of this study do not support the contention that Sts 19 should be excluded from the A. africanus hypodigm. This conclusion concurs with that of most analyses of the specimen (Broom and Robinson, 1950; Dean and Wood, 1982; Wol poff, 1996). However, that the taxonomic affinities of Sts 19 have been the focus of debate requires further examination.

In addition to Kimbel and Rak (1993), others have highlighted the "progressive" or Homo-like aspects of Sts 19. Broom and Robinson (1950) pointed out many humanlike aspects of the specimen that were not shared by other Sterkfontein basicrania: 1) a broad nuchal plane, 2) short basioccipital, 3) a tympanic that serves as the posterior wall of the mandibular fossa, 4) a humanlike lateral pterygoid plate, and 5) humanlike proportions of the posterior cranial fossa. Schepers (1950) also noted the human-like arrangement of the posterior cranial fossa. That such features appear especially Homolike is exacerbated by the fact that the best-preserved Sterkfontein cranium, Sts 5, is decidedly not Homo-like for these characteristics. Clarke (1977) suggested that the differences between Sts 19 and the more pongid-like Sts 5 merely reflect a high degree of intraspecific variation. This was also the position taken by Broom and Robinson: "The skulls were found only about 10 yards apart, and there can be no reasonable doubt that both belong to the samespecies. Clearly there is a very considerable degree of variation in Plesianthropus transvaalensis" (1950: 70). Yet, it is apparent that Sts 5 contributes as much, if not more, to the high degree of 
TABLE 10. Distribution of non-basicranial traits in A. africanus ${ }^{1}$

\begin{tabular}{|c|c|c|}
\hline \multirow{4}{*}{$\begin{array}{l}\text { Trait } \\
\text { Relative brain size } \\
\text { Relative orbit shape } \\
\text { Relative facial structure }\end{array}$} & \multicolumn{2}{|c|}{ Distribution } \\
\hline & Large: Sts 5, Sts 19, Stw 505, MLD 37/38 & Small: Sts 17 , Sts 25 \\
\hline & Broad: Sts 5 & Tall: Sts 71, Stw 505 \\
\hline & $\begin{array}{l}\text { Alveolar prognathism and posteriorly positioned } \\
\text { cheeks: Sts 5, Stw 13, TM } 151\end{array}$ & Flat and vertical face: Sts 71, Stw 252 \\
\hline Evidence of sagittal crest & Yes: Sts 5, Sts 17 & No: Sts 5, Sts 71, Stw 13, Stw 505 \\
\hline Anterior pillars & Strong: Sts 5, Stw 13, Stw 505 & Weak: Sts 5, TM 1512 \\
\hline
\end{tabular}

intraspecific variation as does Sts 19 (see Results section, above).

The distribution of morphological traits among $A$. africanus specimens is indicative of tokogenetic relationships, not cladistic ones. Although the range of variation within A. africanus has been touted as excessive (Kimbel and White, 1988; Kimbel and Rak, 1993), the pattern of variation clearly indicates the presence of only a single species. Wol poff (1996) provides five traits that demonstrate no clear divisions of $A$. africanus into two species. Table 10 lists the distribution of these traits among the specimens assigned to $A$. africanus hypodigm. Furthermore, the distribution of character states in the present study reaffirms the unity of $A$. africanus (see the Results section and Appen$\operatorname{dix} B)$.

\section{CONCLUSION}

This study has failed to support the position that the basicranial specimen Sts 19 should be excluded from A. africanus. However, the study's limitations must be emphasized. Only 12 basicranial characters were used, following Kimbel and Rak's (1993) study. Given the preservation of Sts 19 and other Plio-Pleistocene hominid specimens, this list of characters is extensive, but it is not exhaustive. Future analyses should attempt to include other characters, such as those of the endocranium, occipital, and lateral orbit. Only casts of the hominids were examined in this study. Although all of these were of the highest resolution and quality available, future work needs to be based upon the actual fossils. Furthermore, the systematic analysis may benefit from the inclusion of $A$. robustus and Homo sapiens sensu lato (cf. Wolpoff et al., 1994) samples, since the phylogenetic positions of A. africanus and other Plio-Pleistocene hominids are still unclear. Finally, further interpretations of variation within A. africanus should be made that use species concepts aside from that employed here and by Kimbel and Rak (1993).

Although the full meaning of variation within $A$. africanus is yet unclear, the hypothesis that the basicranial specimens represent a single species cannot be refuted based upon the characters used in this study. When Sts 19 is included in A. africanus, the taxon's level of polymorphism is actually less than that exhibited by Pan troglodytes. Furthermore, Sts 19 shares only one derived feature exclusively with $\mathrm{H}$. habilis. When treated metrically, Sts 19's morphology for this character is not terribly divergent from other $\mathrm{A}$. africanus specimens.

\section{ACKNOWLEDGMENTS}

I thank L. J ellema and B. Latimer of the Cleveland Museum of Natural History and B. Mader of the American Museum of Natural History for their hospitality and for providing access to the invaluable collections in their care. I am indebted to the following individuals, who provided useful criticism and assistance with this project: $\mathrm{K}$. Brandt, T. Crummett, K. Hunley, J . Hawks, S-H. Lee, M. McLaughlin, A. McWaters, J .A. Miller, and M.H. Wolpoff. Useful comments by an anonymous reviewer and the editorial staff of this journal contributed to the final version of this work. I am especially thankful for the extraordinary assistance provided by W. Kimbel. Dr. Kimbel's helpful criticisms and thorough review greatly improved this paper. This project was funded in part by the H. Rackham School of Graduate Studies, University of Michigan. 
APPENDIX A. ThePongid samples

\begin{tabular}{|c|c|c|c|c|}
\hline \multicolumn{2}{|c|}{ Pan troglodytes $\left(\mathrm{N}=48^{1}\right)$} & \multicolumn{3}{|c|}{ Gorilla gorilla $\left(\mathrm{N}=39^{2}\right)$} \\
\hline $\begin{array}{l}\text { American Museum } \\
\text { of Natural History }\end{array}$ & $\begin{array}{c}\text { Cleveland } \\
\text { Museum of } \\
\text { Natural History }\end{array}$ & $\begin{array}{c}\text { Cleveland } \\
\text { Museum of } \\
\text { Natural History }\end{array}$ & $\begin{array}{c}\text { Cleveland } \\
\text { Museum of } \\
\text { Natural History }\end{array}$ & $\begin{array}{c}\text { Paleoanthropology } \\
\text { Laboratory University } \\
\text { of Michigan }\end{array}$ \\
\hline $\begin{array}{r}119770 \\
167341 \\
167342 \\
167344 \\
167346 \\
174860 \\
174861 \\
201464 \\
51202 \\
51203 \\
51207 \\
51209 \\
51376 \\
51379 \\
54330 \\
89351 \\
89354 \\
89355 \\
89406 \\
90189 \\
90191 \\
90293 \\
90297\end{array}$ & 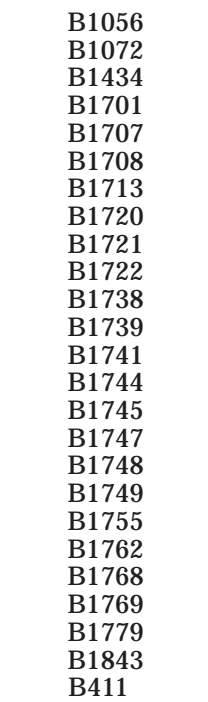 & 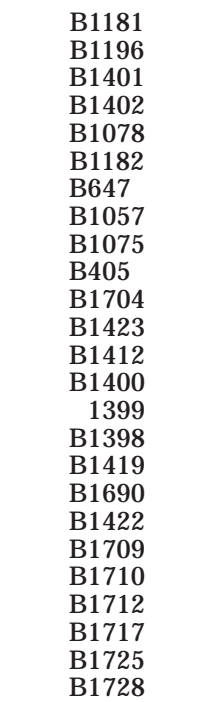 & $\begin{array}{l}\text { B1729 } \\
\text { B1730 } \\
\text { B1731 } \\
\text { B1732 } \\
\text { B1764 } \\
\text { B1756 } \\
\text { B1794 } \\
\text { B } 1846 \\
\text { B1849 }\end{array}$ & $\begin{array}{l}\text { B3424 (cast) } \\
\text { UM “8” } \\
\text { UM no\#3 (cast) } \\
\text { UM no\#1 (cast) } \\
\text { UM no\#2 (cast) }\end{array}$ \\
\hline
\end{tabular}

1 Twenty-six males and 22 females.

2 Ten males and 20 females.

APPENDIX B. Character state distribution among the hominids

\begin{tabular}{|c|c|c|c|c|c|c|c|c|c|c|c|c|}
\hline \multirow[b]{2}{*}{ Specimen } & \multicolumn{12}{|c|}{ Characters $^{1}$} \\
\hline & 1 & 2 & 3 & 4 & 5 & 6 & 7 & 8 & 9 & 10 & 11 & 12 \\
\hline Sts 19 & 1 & 1 & 0 & 2 & 1 & 1 & 1 & 0 & 1 & 1 & 1 & 1 \\
\hline Sts 5 & 1 & 0 & 0 & 1 & 1 & 0 & 0 & 0 & 0 & 0 & 1 & 0 \\
\hline MLD $37 / 38$ & 1 & 1 & 0 & 0 & 1 & 0 & 0 & 0 & 0 & 1 & 1 & 1 \\
\hline Sts 71 & - & 1 & 1 & - & - & 0 & - & 0 & - & 0 & - & 亡 \\
\hline TM 1511 & - & - & $\perp$ & - & - & - & - & 0 & - & - & - & - \\
\hline Stw 505 & 1 & 1 & 0 & 2 & 1 & 1 & - & 0 & - & - & 0 & 1 \\
\hline $\mathrm{OH} 24$ & 2 & 1 & 1 & 2 & 1 & 1 & 0 & 1 & 0 & 1 & 1 & 1 \\
\hline $\mathrm{OH} 13$ & - & 1 & 1 & - & $\perp$ & 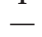 & - & 1 & 1 & \pm & \pm & 亡 \\
\hline L. 894-1 & - & 0 & 0 & - & - & - & - & 1 & - & - & - & - \\
\hline Stw 53 & 1 & 1 & 1 & 2 & 1 & 0 & 1 & 1 & - & - & 1 & 1 \\
\hline ER 1813 & 1 & - & 1 & - & - & 0 & - & 1 & - & 1 & - & 亡 \\
\hline ER 3891 & 1 & 1 & 1 & 2 & - & 1 & - & 1 & - & \pm & - & - \\
\hline SK 847 & - & 1 & 1 & 3 & 1 & 1 & - & 1 & 0 & 1 & 1 & 1 \\
\hline
\end{tabular}

${ }^{1}$ See Table 2 and Methods for character and character state definitions.

\section{LITERATURE CITED}

Aiello L and Dean C (1990) Human Evolutionary Anatomy. New York: Academic.

Brace CL (1988) The Stages of Human Evolution: Human and Cultural Origins. Engelwood Cliffs, N.J : Prentice-Hall.

Broom R and Robinson J T (1950) Further evidence of thestructure of theSterkfontein ape-man, Plesianthropus. Transvaal Museum Memoir. No. 4, Pt. 1.

Cave AJ E (1979) The mammalian temporo-pterygoid ligament. J . Zool. Lond. 188:517-532.
Clarke RJ (1977) The Cranium of the Swartkrans Hominid SK 847 and Its Relevance to Human Origins. Ph.D. thesis, University of Witwatersrand.

Clarke RJ (1985) Australopithecus and early Homo in southern Africa. In E Delson (ed.): Ancestors: The Hard Evidence. New York: Alan R. Liss, pp. 171-177.

Clarke RJ (1988) A new Austral opithecus cranium from Sterkfontein and its bearing on the ancestry of Paranthropus. In FE Grine (ed.): Evolutionary History of the "Robust" Australopithecines. New York: Aldine de Gruyter, pp. 285-292. 
Clarke RL (1994) On some new interpretations of Sterkfontein stratigraphy. S. Afr. J . Sci. 90:211-214.

Cracraft J (1989) Speciation and its ontology: The empirical consequences of alternative species concepts for understanding patterns and processes of differentiation. In D OtteandJ A Endler (eds.): Speciation and its Consequences. Sunderland, MA: Sinauer Associates, pp. 28-59.

Dean MC (1984) Comparative myology of the hominoid cranial base: I. The muscular relationships and bony attachments of the digastric muscle. Folia Primatol. 43:234-248

Dean MC (1985) Comparative myology of the hominoid cranial base: II. The muscles of the prevertebral and upper pharyngeal region. Folia Primatol. 44:40-51.

Dean MC and Wood BA (1982) Basicranial anatomy of Plio-Pleistocene hominids from East and South Africa. Am. J. Phys. Anthropol. 59:157-174.

Ereshefsky M (1989) Where's the species? Comments on the phylogenetic species concepts. Biol. Philos. 4:8996.

Gingerich PD (1984) Primate evolution: evidence from thefossil record, comparative morphology, and molecular biology. Yrbk. Phys. Anthropol. 27:57-72.

Grine FE, Demes B, J ungers WL, and Cole TM (1993) What is the taxonomic affinity of the SK 847 cranium from Swartkrans, South Africa? Am. J . Phys. Anthropol. (Suppl.) 16:99.

Holloway RL (1970) New endocranial values for the australopithecines. Nature 227:199-200.

Holloway RL (1973) Endocranial volumes of early African hominids, the role of the brain in human mosaic evolution. J . Hum. Evol. 2:449-459.

Howell FC (1978) Hominidae. In VS Maglio and HBS Cooke (eds.): Evolution of African Mammals. Cambridge, Mass.: Harvard University Press, pp. 154248.

Hughs AR and Tobias PV (1977) A fossil skull probably of the genus Homo from Sterkfontein, Transvaal. Nature 256:310-312.

Kelly J (1993) The taxonomic implications of sexual dimorphism in Lufengpithecus. In WH Kimbel and LB Martin (eds.): Species, Species Concepts, and Primate Evolution. New York: Plenum.

Kimbel WH (1991) Species, species concepts, and hominid evolution. J . Hum. Evol. 20:335-371.

Kimbel WH and Martin LB (1993) Species, Species Concepts, and Primate Evolution. N ew York: Plenum.

Kimbel WH and Rak Y (1993) The importance of species in paleoanthropology and an argument for the phylogenetic concept of the species category. In WH Kimbel and LB Martin (eds.): Species, Species Concepts, and Primate Evolution. New York: Plenum, pp. 461-484.

Kimbel WH and White TD (1988) Variation, sexual dimorphism, and the taxonomy of Australopithecus. In FE Grine (ed.): Evolutionary History of the "Robust" Australopithecines. New York: Aldine de Gruyter, pp. 175-192.

Kramer A, Donnelly SM, Kidder J H, Ousley SD, and Odah SM (1995) Craniometric variation in largebodied hominoids: Testing the single-species hypothesis for Homo habilis. J. Hum. Evol. 29:443-463.

Kuman K (1994) The archaeology of Sterkfontein-past and present. J. Hum. Evol. 27:471-495.

Le Gros Clark WE (1964) The Fossil Evidence for Human Evolution. Chicago: University of Chicago Press.

Maddison WP and Maddison DR (1992) MacClade: Analysis of Phylogeny and Character Evolution. Sunderland, MA: Sinauer Associates.

Mayden RL (1997) A hierarchy of species concepts: The denouement in the saga of the species problem. In MF Claridge, HA Dawah, and MR Wilson (eds.): Species:
The Units of Biodiversity. London: Chapman and Hall, pp. 381-424.

Mayden RL and Wood RM (1995) Systematics, species concepts, and the evolutionary significant unit in biodiversity and conservation biology. American Fisheries Society Symposium 17:58-113.

Mayr E (1957) Species concepts and definitions. In S Tax (ed.): The Species Problem. American Association for the Advancement of Science Publication 50:1-22.

Nixon KC and Wheeler QD (1990) An amplification of the phylogenetic species concept. Cladistics 6:211223

Owen R (1851) Osteological contributions to the natural history of the chimpanzees (Troglodytes) and orangs (Pithecus). Trans. Zool. Soc. Lond. 4:75-88.

Rak Y (1983) the Australopthecine Face. New York: Academic Press.

Rak Y, Kimbel WH, and Hovers E (1994) A Neandertal infant from Amud Cave, I srael. J . Hum. Evol. 26:313324

Rak Y, Kimbel WH, and Hovers E (1996) On Neandertal autapomorphies discernible in Neandertal infants: A response to Creed-Miles et al. J . Hum. Evol. 39:155158.

Rose KD and Bown TM (1993) Species concepts and species recognition in Eocene primates. In WH Kimbel and LB Martin (eds.): Species, Species Concepts, and Primate Evolution. New York: Plenum, pp. 299-330.

Sarmiento EE (1993) Sts 19 and the origin of the genus Homo. Am J . Phys. Anthropol. (Suppl.) 16:173.

Schepers GWH (1950) The brain casts of recently discovered Plesianthropus skulls. Transvaal Museum Memoir. No. 4, Pt. 2.

Schwartz HP (1995) Skeletal Keys: An Introduction to Human Skeletal Morphology, Devel opment, and Analysis. New York: Oxford University Press.

Strait DS, GrineFE, and Moniz MA (1997) A reappraisal of early hominid phylogeny. J. Hum. Evol. 32:17-82.

Tattersall I (1986) Species recognition in human paleontology. J . Hum. Evol. 15:165-175.

Tattersall i (1992) Species concepts and species identification in human evolution. J . Hum. Evol. 22:341-349.

Tattersall I (1994) Morphology and phylogeny. Evol. Anthropol. 3:40-41.

Tobias PV (1980) "Australopithecus afarensis" and A. africanus: Critique and an alternative hypothesis. Palaeont. Afr. 23:1-17.

Weidenreich F (1943) Theskull of Sinanthropus pekinensis: A comparative study of a primitive hominid skull. Palaeontologia Sinica D(10) (n.s.).

Weidenreich F (1951) Morphology of Solo man. Anthropological Papers of the American Museum of Natural History 43:205-290.

Wol poff MH (1971a) Competitive exclusion among lower Pleistocene hominids: The single species hypothesis. Man 6:601-614.

Wol poff MH (1971b) Is the new composite cranium from Swartkrans a small robust australopithecine? Nature 230:398-401.

Wolpoff MH (1994) Time and phylogeny. Evol. Anthropol. 3:38-39.

Wolpoff MH (1996) Human Evolution. 1996-1997 edition. New York: McGraw-Hill.

Wol poff MH, Thorne AG, J elinek J , and Yinyun Z (1994)

The case for sinking Homo erectus: 100 years of Pithecanthropus is enough! In J L F ranzen (ed.): 100 Years of Pithecanthropus: The Homo erectus Problem. Frankfurt: Forschungsinstitut Senckenberg, pp. 341361

Wood B (1993) Early Homo: How many species? In WH Kimbel and LB Martin (eds.): Species, Species Concepts, and Primate Evolution. New York: Plenum, pp. 485-522. 